\title{
Video Article \\ Experimental Protocol for Biodiesel Production with Isolation of Alkenones as Coproducts from Commercial Isochrysis Algal Biomass
}

\author{
Gregory W. O'Neil ${ }^{1}$, John R. Williams ${ }^{1}$, Julia Wilson-Peltier ${ }^{1}$, Gerhard Knothe ${ }^{2}$, Christopher M. Reddy ${ }^{3}$ \\ ${ }^{1}$ Department of Chemistry, Western Washington University \\ ${ }^{2}$ Agricultural Research Service, United States Department of Agriculture \\ ${ }^{3}$ Department of Marine Chemistry and Geochemistry, Woods Hole Oceanographic Institution
}

Correspondence to: Gregory W. O'Neil at oneilg@chem.wwu.edu

URL: https://www.jove.com/video/54189

DOI: doi:10.3791/54189

Keywords: Environmental Sciences, Issue 112, Algal biofuels, biodiesel, fatty esters, lipids, coproducts, alkenones, Isochrysis

Date Published: 6/24/2016

Citation: O'Neil, G.W., Williams, J.R., Wilson-Peltier, J., Knothe, G., Reddy, C.M. Experimental Protocol for Biodiesel Production with Isolation of Alkenones as Coproducts from Commercial Isochrysis Algal Biomass. J. Vis. Exp. (112), e54189, doi:10.3791/54189 (2016).

\section{Abstract}

The need to replace petroleum fuels with alternatives from renewable and more environmentally sustainable sources is of growing importance. Biomass-derived biofuels have gained considerable attention in this regard, however first generation biofuels from edible crops like corn ethanol or soybean biodiesel have generally fallen out of favor. There is thus great interest in the development of methods for the production of liquid fuels from domestic and superior non-edible sources. Here we describe a detailed procedure for the production of a purified biodiesel from the marine microalgae Isochrysis. Additionally, a unique suite of lipids known as polyunsaturated long-chain alkenones are isolated in parallel as potentially valuable coproducts to offset the cost of biodiesel production. Multi-kilogram quantities of Isochrysis are purchased from two commercial sources, one as a wet paste ( $80 \%$ water) that is first dried prior to processing, and the other a dry milled powder (95\% dry). Lipids are extracted with hexanes in a Soxhlet apparatus to produce an algal oil ("hexane algal oil") containing both traditional fats (i.e., triglycerides, $46-60 \% \mathrm{w} / \mathrm{w})$ and alkenones (16-25\% w/w). Saponification of the triglycerides in the algal oil allows for separation of the resulting free fatty acids (FFAs) from alkenone-containing neutral lipids. FFAs are then converted to biodiesel (i.e., fatty acid methyl esters, FAMEs) by acid-catalyzed esterification while alkenones are isolated and purified from the neutral lipids by crystallization. We demonstrate that biodiesel from both commercial Isochrysis biomasses have similar but not identical FAME profiles, characterized by elevated polyunsaturated fatty acid contents (approximately $40 \% \mathrm{w} / \mathrm{w}$ ). Yields of biodiesel were consistently higher when starting from the Isochrysis wet paste $(12 \% \mathrm{w} / \mathrm{w} \mathrm{vs}$. $7 \% \mathrm{w} / \mathrm{w})$, which can be traced to lower amounts of hexane algal oil obtained from the powdered Isochrysis product.

\section{Video Link}

The video component of this article can be found at https://www.jove.com/video/54189/

\section{Introduction}

There has recently been a great resurgence of interest in biofuels from algae, particularly for the production of liquid fuels such as biodiesel ${ }^{1}$ and other biomass-derived oils. ${ }^{2}$ Proposed benefits include the avoidance of certain food vs. fuel controversies ${ }^{3}$ and reportedly higher productivities and $\mathrm{CO}_{2}$ mitigation capabilities than traditional agricultural crops. ${ }^{4}$ This follows the nearly 20 year United States Department of Energy's Aquatic Species Program (ASP) started in 1978 for the purpose of investigating transportation fuel from algae. As outlined in Sheehan's report, ${ }^{5}$ the program ended in 1996 primarily because projected costs were not competitive with crude petroleum at that time $(\$ 18.46$ per barrel $(159 \mathrm{~L}))$. While the cost of petroleum has increased dramatically since then $(\$ 87.39 \text { per barrel in } 2014)^{6}$, which is connected to the renaissance in algal biofuel research, some have argued that nonetheless algal biofuels will prove too costly. ${ }^{7}$ As one strategy to offset biofuel production costs, the notion of value-added coproducts has emerged among both critics $^{7,8}$ and proponents ${ }^{9,10}$ and features as one of the key reasons for pursuing algal biofuels in the United States Department of Energy (DOE) "National Algal Biofuels Technology Roadmap". ${ }^{11}$

Here we describe a method for the coproduction of two separate fuel streams from commercial Isochrysis microalgae. We have focused on Isochrysis in part because it is already produced industrially, harvested for purposes of mariculture, and also because Isochrysis is one of only a few species of algae that in addition to traditional lipids (i.e., fatty acids) biosynthesize a unique class of compounds known as polyunsaturated long-chain alkenones. ${ }^{12}$ Alkenone structures are characterized by very long hydrocarbon chains (36-40 carbons), two to four non-methylene interrupted trans-double bonds, and a methyl or ethyl ketone (Figure 1). Alkenone unsaturation is sensitive to the algae growing temperature, ${ }^{13,14}$ such that the proportion of the diunsaturated C37 methyl alkenone (the so-called "unsaturation index") can be used as a proxy for past sea surface temperatures. ${ }^{15-20}$ Alkenones are thought to reside in cytoplasmic lipid bodies and can be more abundant than triglycerides (TAGs). ${ }^{21,22}$ Under nitrogen or phosphorous limitation, up to $10-20 \%$ of cell carbon in the stationary phase is accumulated as alkenones. ${ }^{23,24}$ From an evolutionary standpoint, alkenones may have been favored over TAGs because their trans-double bond geometry provides a more stable form of energy storage. ${ }^{21}$ 


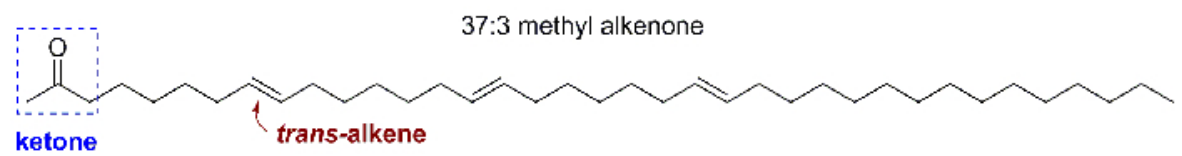

Figure 1. Structures of polyunsaturated long-chain alkenones. Common alkenone methyl 37:3 isolated from Isochrysis exemplifying long hydrocarbon chain lengths (36 - 40 carbons), trans non-methylene interrupted double bonds, and terminating in a methyl or ethyl ketone. Nomenclature is similar to fatty acids where \#:\# refers to number of carbons:number of double bonds. Please click here to view a larger version of this figure.

We argue that alkenones represent a promising renewable carbon feedstock from a common algae with a history of industrial cultivation. ${ }^{25}$ Biodiesel produced directly from the total lipid extract of Isochrysis contains a significant amount (10-15\% w/w) of alkenones and contamination by these high-melting compounds results in poor cold flow fuel properties. However, using the saponification/extraction techniques described here, alkenones can be removed and recovered thereby improving the biodiesel quality while producing a secondary product stream. Recently we demonstrated the conversion of alkenones to a liquid fuel by cross-metathesis with 2-butene (butenolysis). ${ }^{26}$ The butenolysis reaction employs a commercial ruthenium metathesis-initiator, occurs rapidly at low temperature, and cleanly delivers a predictable mixture of jet fuel range hydrocarbons. This reaction is performed in parallel with biodiesel synthesis from fatty acids, representing the first steps toward a "biorefinery" approach ${ }^{27}$ for commercially viable Isochrysis biofuel production.

\section{Protocol}

\section{Microalgae and Biomass Preparation}

Note: The marine microalgae Isochrysis sp. "T-iso" used in the present study can be purchased (see List of Materials). Multi-kilogram quantities of Isochrysis can be purchased as a frozen wet paste (Iso-paste) containing approximately $80 \%$ water and $20 \%$ biomass, and is dark green/near black in color with a pungent odor smelling of the sea. Isochrysis can also be purchased as a dry (95\% dry) yellow-brown powder (Iso-powder) with a similar odor.

1. In order to dry the /sochrysis paste, open a $1 \mathrm{~kg}$ package by cutting a 1 - 2 inch hole in the corner of the plastic packaging using scissors.

2. Squeeze approximately $300 \mathrm{~g}$ of this Isochrysis paste through the hole into a $150 \mathrm{~mm} \times 75 \mathrm{~mm}$ crystallizing dish to create a thin layer ( 20 $\mathrm{mm})$.

3. Leave the paste to air-dry at room temperature until it becomes dry and flaky (typically, $48-96 \mathrm{hr}$ ). Note: Actual drying times may vary and are dependent on temperature. However, no difference was noticed in the yields or product quality with even longer drying times (up to two weeks). The drying process may also be made more uniform and/or accelerated by placing the crystallizing dish on a warm plate $\left(30-40^{\circ} \mathrm{C}\right)$.

4. Scrape the dry biomass from the crystallizing dish using a spatula and collect into a cellulose extraction thimble (Length: $123 \mathrm{~mm}, 43 \mathrm{~mm}$ ID). Record the weight of the dry Isochrysis biomass.

\section{Soxhlet Extraction of Dry Isochrysis Biomass}

1. Load an Isochrysis-containing cellulose extraction thimble (typically 50 - $60 \mathrm{~g}$ dry biomass) into a Soxhlet extraction apparatus.

2. Fill the Soxhlet flask with hexanes $(400 \mathrm{ml}$ ), turn on the condenser water and heat source, and allow the Soxhlet to cycle for $24-48 \mathrm{hr}$ (until the color of the solvent has gone from dark green to a faint yellow).

3. Turn off the heat and allow the apparatus to cool to room temperature, then disconnect the flask from the Soxhlet extractor.

4. Remove the hexanes using a rotary evaporator and record the weight of the hexanes-extractable material ("hexane algal oil" (h-AO))

\section{Saponification of the Algal Oil and Separation of Fatty Acids and Neutral Lipids}

1. Redissolve the $\mathrm{h}-\mathrm{AO}$ in the same round bottom flask from Step 2.4 above with methanol:dichloromethane $(2: 1$, volume $=10 \times \mathrm{mass}$ of algal oil).

2. Add a stir bar and attach a reflux condenser (Coil: $500 \mathrm{~mm}$ length).

3. Add $\mathrm{H}_{2} \mathrm{O}$ (volume $=2.67 \times$ mass of algal oil) and $\mathrm{KOH}\left(50 \% \mathrm{w} / \mathrm{w}\right.$ algal oil) and heat the contents with stirring to $60^{\circ} \mathrm{C}$ for $3 \mathrm{hr}$.

4. After cooling to room temperature, remove the organic solvents (methanol and dichloromethane) on a rotary evaporator.

5. Transfer the remaining aqueous mixture by pouring into a 1-L separatory funnel. Add hexanes (equivalent in volume to the aqueous solution), shake the separatory funnel, and allow the layers to separate.

6. Drain the lower aqueous layer into an Erlenmeyer flask, and pour off the top organic phase into a separate Erlenmeyer.

7. Repeat steps 3.5 and 3.6 until the organic layer is colorless (typically 1-2 more times).

8. Concentrate the combined organic extracts on a rotary evaporator to isolate the neutral lipids as a greenish solid $\left(\mathrm{mp} . \approx 60-70{ }^{\circ} \mathrm{C}\right.$ ).

9. Acidify the aqueous phase with $\mathrm{HCl}(6 \mathrm{M}$, until $\mathrm{pH} \sim 2$ as indicated by $\mathrm{pH}$ paper).

10. Extract the free fatty acids (FFAs) from the acidified aqueous phase with hexanes (equivolume to the aqueous phase) using a $1 \mathrm{~L}$ separatory funnel as described in steps 3.5 and 3.6.

11. Remove the hexanes on a rotary evaporator to obtain the FFAs as a dark green near-black oily residue (liquid at temperatures $>30{ }^{\circ} \mathrm{C}$ ).

\section{Acid-catalyzed Esterification of Free Fatty Acids and Production of a Green Biodiesel}

1. Transfer the FFAs using methanol:chloroform (1:1,6 $\mathrm{x}$ volume of algal oil) to first dissolve the FFAs and then by pouring into a thick-walled high pressure reaction flask equipped with a stir bar. 
2. Add concentrated $\mathrm{H}_{2} \mathrm{SO}_{4}(20 \% \mathrm{w} / \mathrm{w}$ algal oil $)$, seal the flask, and heat the mixture to $90{ }^{\circ} \mathrm{C}$ while stirring for $1 \mathrm{hr}$.

3. After cooling to room temperature, transfer the mixture by pouring into a separatory funnel.

4. Add $\mathrm{H}_{2} \mathrm{O}(2 \times$ volume of algal oil $)$, shake the separatory funnel, and allow the phases to separate.

5. Drain the bottom layer into a pre-weighed round bottom flask and concentrate on a rotary evaporator. Record the mass of the resulting biodiesel.

6. Analyze the fatty acid profile by gas chromatography with flame-ionization detector (GC-FID) ${ }^{28}$ (gas chromatograph equipped with a DB-88 [(88\% cyanopropyl) methylarylpolysiloxane] column (30 m x $0.25 \mathrm{~mm}$ ID x $0.20 \mu \mathrm{m}$ film thickness).

Note: Common fatty acid methyl esters are verified by retention time comparison with authentic samples obtained commercially. Additionally, gas chromatography-mass spectrometry (GC-MS; gas chromatograph coupled to a mass selective detector) is performed under identical conditions of temperature program and column to analyze components such as C18:4 for which no authentic standards are available with the results applied to GC quantitation.

\section{Biodiesel Decolorization}

1. Heat the dark green colored biodiesel to $60^{\circ} \mathrm{C}$ in a round bottom flask equipped with a stir bar.

2. Add montmorillonite $\mathrm{K} 10$ (MK10) powder $(10-20 \% \mathrm{w} / \mathrm{w}$ of the biodiesel) and stir for $1 \mathrm{hr}$.

3. Remove the round bottom from the heat and allow the solution to cool to room temperature.

4. Prepare a filtration apparatus consisting of a round bottom flask and filter funnel containing a cellulose filter paper (Ash $0.007 \%$ ).

5. Pour the cooled decolorized biodiesel through the filter funnel using a minimal amount of hexanes to rinse the round bottom flask.

6. Disconnect the filter funnel from the round bottom flask (this now contains a hexanes solution of the decolorized biodiesel) and remove the hexanes with a rotary evaporator to afford an orange/red biodiesel.

7. Store samples at $4{ }^{\circ} \mathrm{C}$ during which time some settling of insoluble material $(\sim 10 \% \mathrm{w} / \mathrm{w})$ will occur.

8. Remove the insoluble material by decanting or filtration as described in step 5.4 and 5.5 to produce a clear homogeneous biodiesel for analysis.

\section{Isolation and Purification of Alkenones from the Neutral Lipids}

1. Dissolve the neutral lipids (from Step 3.8) in a minimal amount of dichloromethane (approximately $50 \mathrm{ml}$ for $10 \mathrm{~g}$ neutral lipids) and add the solution with a pipet to the top of a chromatography column (O.D $60 \mathrm{~mm}$, ID $55 \mathrm{~mm}$, length 18") containing silica gel (230-400 mesh, $100 \mathrm{~g}$ ).

2. Elute the solution through the silica with pressure ( $\sim 5 \mathrm{psi})$ using dichloromethane (approximately $150 \mathrm{ml})$ as solvent and collect the eluent in a $250 \mathrm{ml}$ round bottom flask.

3. Remove the dichloromethane with a rotary evaporator to give an orange-colored solid.

4. Recrystallize the solid using hexanes by adding approximately $100 \mathrm{ml}$ of boiling hexanes followed by incremental additional amounts of boiling hexanes until the solution is homogeneous (total volume $\sim 150 \mathrm{ml}$ ). Then, slowly cool the solution to room temperature to promote crystallization.

5. Collect the crystallized alkenones using a filtration apparatus as described in step 5.4 using a small amount of cold $\left(0{ }^{\circ} \mathrm{C}\right)$ hexanes to rinse the flask.

\section{Representative Results}

Prior to processing, the Isochrysis paste (Iso-paste) was first dried. This was conveniently accomplished on larger scale by adding the Iso-paste to a large crystallizing dish and allowing the material to air-dry at room temperature. During drying, some pooled water forms (generally reddish colored) that can be removed by decanting or pipetting to accelerate the drying process. After approximately 48 - $96 \mathrm{hr}$, the now dry Isochrysis could be scraped out of the crystallizing dish and obtained as a black/green flaky material with a seaweed-like smell (Figure 2). Yields of dry biomass were generally $20 \% \mathrm{w} / \mathrm{w}$ of the paste as advertised. By contrast, the powdered Isochrysis product (Iso-powder) was a yellow-brown, finely milled, dry powder ( $95 \%$ dry) that was used directly without further processing (Figure 2).

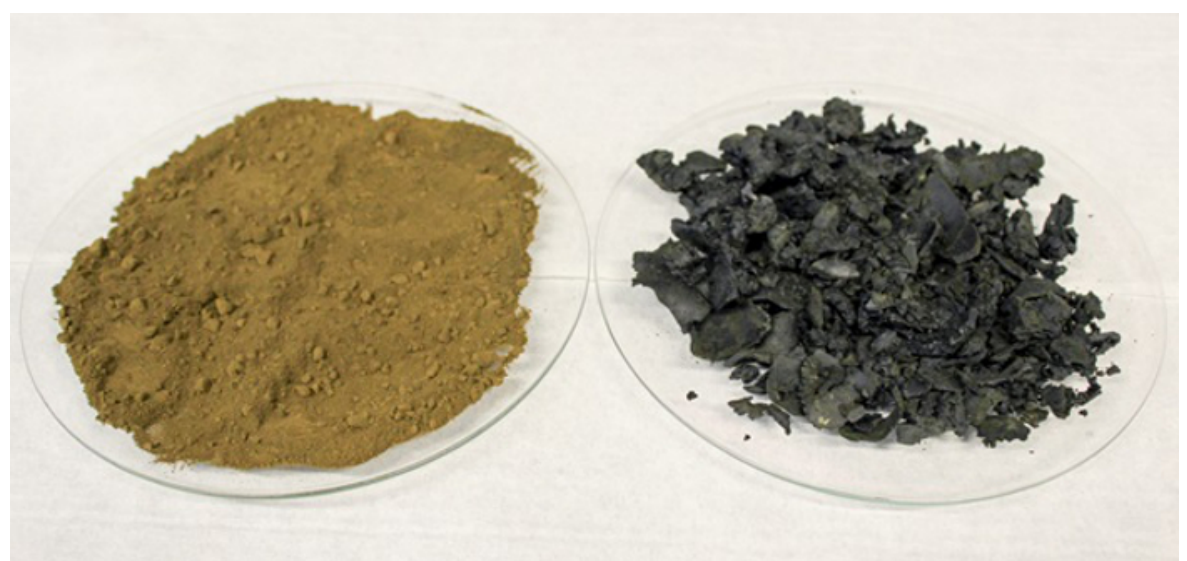

Figure 2. Comparison of commercial Isochrysis. Isochrysis paste ( $80 \%$ wet) is spread along the bottom of a crystallizing dish and left to airdry at room temperature for $48-96 \mathrm{hr}$ before processing. The resulting dried Isochrysis is obtained as a dark-colored flaky material (right) that is different in appearance than the commercial dry powder /sochrysis (left). Please click here to view a larger version of this figure. 
Extraction of either the dried Iso-paste or Iso-powder by Soxhlet with hexanes gave, after removal of the hexanes, algal oils (h-AO) that were similar in appearance as dark-green/near-black solids (mp. $\left.\sim 50-60{ }^{\circ} \mathrm{C}\right)$. Yields of h-AO when starting from the paste ("Iso-paste-hAO") were typically $20 \% \mathrm{w} / \mathrm{w}$ of the dry Isochrysis biomass, consistent with our previous results, ${ }^{26}$ whereas yields of h-AO by Soxhlet extraction of the commercial powdered Isochrysis ("Iso-powder-hAO") were 15\% w/w (Table 1).

\begin{tabular}{|l|l|l|l|}
\hline Product (g) & Iso-paste & Iso-powder-1 & Iso-powder-2 \\
\hline Dry Biomass & 30 & 20 & 20 \\
\hline Hexane Algal Oil & 5.86 & 2.87 & 3.11 \\
\hline FFAs & 3.52 & 1.34 & 1.38 \\
\hline Neutral lipids & 2.34 & 1.38 & 1.61 \\
\hline Alkenones & 0.94 & 0.63 & 0.74 \\
\hline $\begin{array}{l}\text { Notes: Iso-powder-1 and Iso-powder-2 represent results from two samples of powdered Isochrysis that were processed in parallel. For other } \\
\text { reports with yields of these products from Iso-paste see references 26, 32, and 33. }\end{array}$ \\
\hline
\end{tabular}

\section{Table 1. Product yields from commercial Isochrysis biomass.}

Acylglycerols in the h-AO were converted to the corresponding water-soluble carboxylate salts (i.e., soaps) upon addition of aqueous $\mathrm{KOH}$ in methanol/ $\mathrm{CH}_{2} \mathrm{Cl}_{2}$. Neutral lipids including alkenones were then extracted from this aqueous mixture by selective partitioning with hexanes. After removal of the neutral lipids, reacidification of the soaps then produced the corresponding free fatty acids (FFAs) that could be similarly extracted from the aqueous phase with hexanes. The overall mass recoveries for combined FFAs and neutral lipids from either Iso-pastehAO or Iso-powder-hAO were consistently near quantitative. However, the ratio of products (i.e., neutral lipids + FFAs) was different. From the Iso-paste-hAO we obtained 60\% (w/w) FFAs and $40 \%$ (w/w) neutral lipids (Table 1). Conversely, Iso-powder-hAO proved enriched in neutral lipids (average $=54 \%$ neutral lipids $+46 \%$ FFAs) as detailed in Table 1.

Esterification of the FFAs with $\mathrm{H}_{2} \mathrm{SO}_{4}$ and methanol then produced fatty acid methyl esters (FAMEs, i.e., biodiesel) as a dark green near black oily liquid in greater than $90 \%$ yield (Figure 3). Decolorization by heating over Montmorillonite K10 29 (MK10) clay then gave a yellow/ orange product, similar in appearance to other commercial biodiesel fuels (see List of Materials) (Figure 3). Results from the FAME analysis of decolorized Isochrysis biodiesel fuels are shown in Table 2.

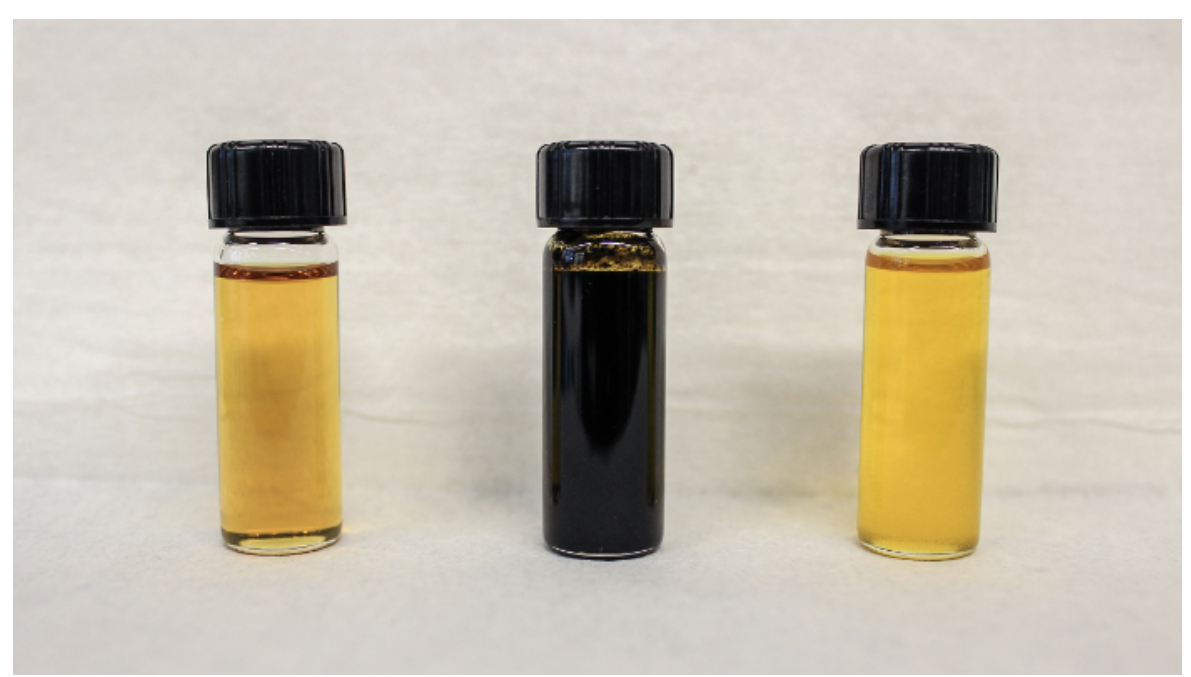

Figure 3. Comparison of Isochrysis and soybean biodiesel fuels. Green Isochrysis biodiesel (middle) is produced by esterification of extracted and purified free fatty acids. Decolorization produces a product (right) with similar properties to commercial biodiesel (left). Please click here to view a larger version of this figure. 


\begin{tabular}{|c|c|c|}
\hline FAME $^{A}$ & Iso-paste & Iso-powder \\
\hline $14: 00$ & 16.4 & 19.4 \\
\hline 14:01 & - & 0.3 \\
\hline 15:00 & trace & 0.3 \\
\hline 16:00 & 10.1 & 8.8 \\
\hline $16: 1 \Delta 9$ & 7.6 & 5.5 \\
\hline 16:02 & ND & 0.3 \\
\hline 16:03 & ND & 0.5 \\
\hline 18:00 & Trace & 0.2 \\
\hline $18: 1^{B}$ & 12.1 & 14.3 \\
\hline 18:02 & 8.1 & 7.1 \\
\hline $18: 3^{C}$ & 8.5 & 13.5 \\
\hline 18:04 & 19.8 & 10.4 \\
\hline 18:05 & $\mathrm{ND}$ & 3 \\
\hline 20:05 & ND & - \\
\hline $22: 05$ & ND & 2 \\
\hline 22:06 & 6.9 & 11 \\
\hline$\Sigma^{\mathrm{D}}$ & 89.8 & 96.2 \\
\hline
\end{tabular}

Table 2. FAME composition of biodiesel produced from commercial Iso-past and Iso-powder Isochrysis biomass.

Neutral lipids were obtained as a greenish solid mixture at $40 \% \mathrm{w} / \mathrm{w}$ from the Iso-paste-hAO and $54 \%$ (avg.) from the Iso-powder-hAO

(Table 1). Filtering the dissolved neutral lipids through silica using DCM gave after removal of the solvent, a reddish/orange solid that could be recrystallized with hexanes to afford analytically pure alkenones as a white solid. This procedure resulted in $16 \%$ (w/w) isolated yield of alkenones from Iso-paste-hAO and 25\% yield from Iso-powder-hAO (Table 1).

\section{Discussion}

Isochrysis is one of only a select number of algal species farmed industrially, harvested as a primary component of shellfish feed, and therefore representative of the scale necessary for biofuel production. The availability of the algae utilized and standard methods employed in this study, make the protocol presented widely accessible to other groups for further investigations. Critical steps include air-drying the algae (as opposed to lyophilizing ${ }^{33}$ ), solvent extractions, saponification, and esterification. Through these operations one can examine yields of lipids and other coproducts from the various /sochrysis available ${ }^{30}$. It is anticipated that these may differ as a result of differing strains and cultivation methods, ${ }^{31}$ and may also be impacted by the nature of the product and any additional processing (e.g., drying or freezing) utilized by the supplier. As we demonstrate here, the protocol developed can be successfully applied to different types of Isochrysis products, ranging from a wet paste to a dry milled powder. Yields of biodiesel were however lower from the powdered biomass $(7 \% \mathrm{w} / \mathrm{w}$ dry biomass vs. $12 \% \mathrm{w} / \mathrm{w}$ from the dried paste), which corresponds with lower amounts of algal oil (h-AO) extracted. This may suggest that an alternative extraction protocol ${ }^{32}$ other than a Soxhlet apparatus may be better suited for dry powdered Isochrysis products. The Isochrysis powder used in this study is advertised as containing $23-25 \%$ lipids, which similar to what we have experimentally obtained from dried Isochrysis paste. ${ }^{33,34,26}$

Despite the different colors of the starting dry biomass, the Iso-paste-hAO and Iso-powder-hAO were essentially indistinguishable, both dark green/near black solids with melting points of approximately $50^{\circ} \mathrm{C}$. Interestingly, the ratio of FFAs to neutral lipids within the two hexane extracts was different. After saponification and separation of the neutral lipids, we obtained $60 \%$ (w/w) FFAs and $40 \%$ (w/w) neutral lipids from the Isopaste-hAO. The Iso-powder-hAO produced on average $46 \%(\mathrm{w} / \mathrm{w})$ FFAs and $54 \%(\mathrm{w} / \mathrm{w})$ neutral lipids. The results suggest that either the starting powdered biomass may contain higher amounts of neutral lipids relative to FA derivatives than the Isochrysis paste, or that Soxhlet extraction of powdered Isochrysis is somewhat selective for neutral lipids.

Not only were the yields of products obtained from the two commercial Isochrysis biomasses different, but also the fatty acid profiles of the resulting biodiesel. This is important, as the fuel properties of a biodiesel are directly dependent on the nature and contents of individual FAMEs. ${ }^{35}$ To be commercialized, all biodiesel must conform to the standards described in the documents ASTM D6751 or EN 14214 in the U.S or Europe respectively. Specifications include ranges for lubricity and kinematic viscosity, and minimum values for cetane number and oxidative stability. Other important recommendations are related to cold flow properties in the form of a cloud point (CP) or cold filter plugging point (CFPP). We have previously reported results from the comprehensive fuel testing of biodiesel prepared from Iso-paste. ${ }^{36} \mathrm{Since}$ the FAME profile of biodiesel produced from the Iso-powder in this study is similar to those previously tested, we can predict certain fuel properties to be similar for both biodiesel fuels. For instance, polyunsaturated fatty acids (PuFAMEs, more than two double bonds) account for approximately $40 \%$ of both FAME mixtures $(35.2 \%$ and $39.9 \%$, Table 2$)$. This will result in poor oxidative stability and favorable cold-flow. ${ }^{35}$ There are, however, 
slight differences in the FAME profiles of the two biodiesel fuels. Biodiesel produced from the powdered Isochrysis contained higher amounts of $14: 0$ (19.4 mg/g vs. $16.4 \mathrm{mg} / \mathrm{g}), 18: 3$ (13.5 mg/g vs. $8.5 \mathrm{mg} / \mathrm{g})$, and 22:6 (11.0 mg/g vs. $6.9 \mathrm{mg} / \mathrm{g})$ FAMEs, yet lower amounts of $18: 4$ (10.4 mg/ $\mathrm{g}$ vs. $19.8 \mathrm{mg} / \mathrm{g}$ ). The extent of the impact of these differences on the various fuel properties contained in the ASTM standards remains to be investigated.

The initial biodiesel obtained from both commercial Isochrysis algae were similarly dark green in color which can be explained by the presence of chlorophylls. ${ }^{36}$ Chlorophyll and its derivatives have been reported to have a negative effect on the stability of vegetable oils and their corresponding biodiesel fuels. ${ }^{36,29}$ Based on the method of Issariyakul and Dalai for decolorizing greenseed canola oil in connection with biodiesel production, ${ }^{29}$ stirring our green biodiesel over $10 \%(\mathrm{w} / \mathrm{w}) \mathrm{MK} 10$ at $60{ }^{\circ} \mathrm{C}$ for $1 \mathrm{hr}$ resulted in a dramatic reduction in pigment content by visual inspection (ref. Figure 2). Mass recoveries from the decolorization process were on average $90 \%$.

Yields of purified alkenones from Iso-paste-hAO and Iso-powder-hAO neutral lipids were comparable at $40 \%$ and $46 \%$ w/w respectively (Table 1). Since neutral lipids represent a higher proportion of material contained in the Iso-powder-hAO (54\% w/w vs. $40 \% \mathrm{w} / \mathrm{w})$, alkenone yield from the Iso-powder-hAO exceeds the Iso-paste-hAO alkenone yield by approximately $10 \%$ ( $25 \% \mathrm{w} / \mathrm{w}$ vs. $16 \%$ w/w). However, considering that yields of the Iso-powder-hAO itself were lower than Iso-paste-hAO (15\% vs. $20 \% \mathrm{w} / \mathrm{w}$ ), overall yields of alkenones from both dry Isochrysis biomasses are more similar $(0.2 \times 0.4 \times 0.4=3.2 \% \mathrm{w} / \mathrm{w}$ from dried Isochrysis paste and $0.15 \times 0.54 \times 0.46=3.7 \%$ from $/$ sochrysis powder $)$

\section{Disclosures}

Mention of trade names or commercial products in this publication is solely for the purpose of providing specific information and does not imply recommendation or endorsement by the U.S. Department of Agriculture. USDA is an equal opportunity provider and employer.

\section{Acknowledgements}

This work was supported by the National Science Foundation (CHE-1151492), the Northwest Advanced Renewables Alliance (fellowship to J. Wilson-Peltier), and through a private donation from friends of WHOI. We thank Kevin R. Steidley and Kim Ascherl (USDA / ARS / NCAUR) for excellent technical assistance.

\section{References}

1. Ahmad, A.L., Mat Yasin, N.H., Derek, C.J.C., Lim, J.K. Microalgae as a sustainable energy source for biodiesel production: A review. Renew. Sustain. Energy Rev. 15(1), 584-593 (2011).

2. Vardona, D. R., Sharmab, B.K., Blazinaa, G.,V., Rajagopalanb, K., Strathmann, T.J. Thermochemical conversion of raw and defatted algal biomass via hydrothermal liquefaction and slow pyrolysis. Bioresour. Technol. 109, 178-187 (2012).

3. Tenenbaum, D.J. Food vs fuel: Diversion of crops could cause more hunger. Environ. Health Perspect. 116, A254-A257, PMCID: PMC2430252 (2008).

4. Pienkos, D.T., Darzins, A. The promise and challenges of microalgal-derived biofuels. Biofuels, Bioprod. Biorefin. 3(4), 431-440 (2009)

5. First Crude Oil Purchase Price. U.S Energy Information Administration. http://www.eia.gov/dnav/pet/hist/LeafHandler.ashx? $\mathrm{n}=\mathrm{PET} \& \mathrm{~s}=\mathrm{F} 000000 \_3 \& \mathrm{f}=\mathrm{A}$. accessed September 30, 2015, (2015).

6. Sheehan, J., Dunahay, T., Sheehan, J., Dunahay, T., Benemann, J., Roessler, P.A. A look back at the U.S. Department of Energy's Aquatic Species Program: Biodiesel from algae. National Renewable Energy Laboratory, report NREL/TP-580-24190 (1996).

7. Petkov, G., Ivanova, A., Iliev, I., Vaseva, I. A critical look at the microalgae biodiesel. Eur. J. Lipid Sci. 114(2), 103-111 (2012)

8. Beilen, J.B. Why microalgal biofuels won't save the internal combustion engine. Biofuels, Bioprod. Biorefin. 4, 41-52 (2010).

9. Chisti, Y. Biodiesel from microalgae. Biotechnol. Adv. 25(3), 294-306, (2007).

10. Wijfles, R.H., Barbosa, M.J. An outlook on microalgal biofuels. Science. 329, 796-799 (2010).

11. Ferrell, J. Sarisky-Reed, V. National Algal Biofuels Technology Roadmap. (Eds. D. Fishman, R. Majumdar, J. Morello, R. Pate, J. Yang), United States Department of Energy, http://www1.eere.energy.gov/bioenergy/pdfs/algal_biofuels_roadmap.pdf (accessed August 24, 2015) (2010).

12. Patterson, G.W., Tsitsa-Tsardis, E., Wikfors, G.H., Gladu, P.K., Chitwood, D.J., Harrison, D. Sterols and alkenones of Isochrysis. Phytochem. 35(5), 1233-1236 (1994).

13. Volkman, J.K., Eglinton, G., Corner, E.D.S. Long-chain alkenes and alkenones in the marine coccolithophorid Emiliania huxleyi. Phytochem. 19, 2619-2622 (1980)

14. Conte, M.H., Thompson, A., Lesley, D., Harris, R.P. Genetic and physiological influences on the alkenone/alkenoate versus growth temperature relationship in Emiliania huxleyi. and Gephyrocapsa Oceanica. Geochim. Cosmochim. Acta. 62(1), 51-68 (1998).

15. Brassell, S.C., Eglinton, G., Marlowe, I.T., Pflaumann, U., Sarnthein, M. Molecular stratigraphy: a new tool for climatic assessment. Nature. 320, 129-133 (1986).

16. Marlowe, I.T., Brassell, S.C., Eglinton, G., Green, J.C. Long chain unsaturated ketones and esters in living algae and marine sediments. Org. Geochem. 6, 135-141 (1984).

17. Prahl, F.G., Wakeham, S.G. Calibration of unsaturation patterns in long-chain ketone compositions for palaeotemperature assessment. Nature. 330, 367-369 (1987).

18. Eglinton, G., Bradshaw, S.A., Rosell, A., Sarnthein, M., Pflaumann, U., Tiedemann, R. Molecular record of secular sea surface temperature changes on 100-year timescales for glacial terminations I, II and IV. Nature. 356, 423-426 (1992).

19. Kirst, G., Ruhland, G., von Storch, I., Rosell-Melé, A. Calibration of the alkenone paleotemperature index U37K' based on core-tops from the eastern South Atlantic and the global ocean $\left(60^{\circ} \mathrm{N}-60^{\circ} \mathrm{S}\right)$. Geochim. Cosmochim. Acta. 62(10), 1757 - 1772 (1998).

20. Volkman, J.K., Barrerr, S.M., Blackburn, S.I., Sikes, E.L. Alkenones in Gephyrocapsa oceanica.: Implications for studies of paleoclimate. Geochim. Cosmochim. Acta. 59(3), 513-520 (1995). 
21. Eltgroth, M.L., Watwood, R.L., Wolfe, G.V. Production and cellular localization of neutral long-chain lipids in the haptophyte algae /sochrysis Galbana. and Emiliania Huxleyi.'J. Phycol. 41, 1000-1009 (2005).

22. Volkman, J.K., Everitt, D.A., Allen, D.I. Some analyses of lipid classes in marine organisms, sediments and seawater using thin-layer chromatography-flame ionisation detection. J. Chromatogr. A. 356, 147-162 (1986).

23. Epstein, B. L.; D'Hondt, S.; Quinn, J. G.; Zhang, J.; Hargraves, P. An effect of dissolved nutrient concentrations on alkenone-based temperature estimates. Paleoceanography. 13(2), 122-126 (1998).

24. Prahl, F.G., Sparrow, M.A., Wolfe, G.V. Physiological impacts on alkenone paleothermometry. Paleoceanogaphy. 18(2), 1025-1031 (2003).

25. Sachs, D., Sachs, J.P. Inverse relationship between $\mathrm{D} / \mathrm{H}$ fractionation in cyanobacterial lipids and salinity in Christmas Island saline ponds. Geochim. Cosmochim. Acta. 72(25), 793-806 (2008).

26. Neil, G.W., Culler, A.R., Williams, J.R., Burlow, N.P., Gilbert, G.J., Carmichael, C.A., Nelson, R.K., Swarthout, R.F., Reddy, C.M. Production of jet fuel range hydrocarbons as a coproduct of algal biodiesel by butenolysis of long-chain alkenones. Energy Fuels. 29(2), 922-930 (2015).

27. Foley, P.M., Beach, E.S., Zimmerman, J.B. Algae as a source of renewable chemicals: opportunities and challenges. Green Chem. 13, 1399-1405 (2011).

28. Razon, L.F., Bacani, FT., Evangelista, R.L., Knothe, G. Fatty acid profile of kenaf seed oil. J. Am. Oil Chem. Soc. 90(6), 835-840 (2013).

29. Issariyakul, T., Dalai, A.K. Biodiesel production from greenseed canola oil. Energy Fuels. 24, 4652-4658 (2010).

30. Nalder, T.D., Miller, M.R., Packer, M.A. Changes in lipid class content and composition of Isochrysis. sp. (T-Iso) grown in batch culture. Aquacult. Int. 23, 1293-1312 (2015).

31. Mercer, P., Armenta, R.E., Developments in oil extraction from microalgae. Eur. J. Lipid Sci. Technol. 113(5), 539-547 (2011).

32. Neil, G.W., Carmichael, C.A., Goepfert, T.J., Fulton, J.M., Knothe, G., Lau, C.P-L., Lindell, S. R., Mohammady, N.G-E., Van Mooy, B.A.S., Reddy, C.M. Beyond fatty acid methyl esters: expanding the renewable carbon profile with alkenones from Isochrysis.sp. Energy Fuels. 26, 2434-2441 (2012).

33. Neil, G.W., Knothe, G., Williams, J.R., Burlow, N.P., Culler, A.R., Corliss, J.M., Carmichael, C.A., Reddy, C.M. Synthesis and analysis of an alkenone-free biodiesel from Isochrysis. sp. Energy Fuels. 28(4), 2677-2683 (2014).

34. Knothe, G. Dependence of biodiesel fuel properties on the structure of fatty acid alkyl esters. Fuel Process. Technol. 86, 1059-1070 (2005).

35. Valenzuela-Espinoza, E., Millán-Núñez, R., Núñez-Cebrero, F. Protein, carbohydrate, lipid and chlorophyll a content in Isochrysis aff. galbana (clone T-Iso) cultured with a low cost alternative to the f/2 medium. Aquacult. Eng. 25, 207-216 (2002).

36. Kulkarni, M.G., Dalai, A.K., Bakshi, N.N. Utilization of green seed canola oil for biodiesel production. J. Chem. Technol. Biotechnol. 81, 1886-1893 (2006). 